\title{
Anti-inflammatory and detoxification activities of some Ipomoea species determined by ion channel inhibition and their phytochemical constituents
}

\author{
Unchaleeporn Ameamsri ${ }^{\mathrm{a}}$, Tawatchai Tanee ${ }^{\mathrm{b}}$, Arunrat Chaveerach $^{\mathrm{a}}$, Steve Peigneur ${ }^{\mathrm{c}}$, Jan Tytgat ${ }^{\mathrm{c}}$, \\ Runglawan Sudmoon ${ }^{\mathrm{d}, *}$ \\ a Department of Biology, Faculty of Science, Khon Kaen University, Khon Kaen 40002 Thailand \\ b Faculty of Environment and Resource Studies, Mahasarakham University, Maha Sarakham 44150 \\ Thailand \\ c Toxicology and Pharmacology, University of Leuven (KU Leuven), Leuven, Belgium \\ d Faculty of Law, Khon Kaen University, Khon Kaen 40002 Thailand
}

*Corresponding author, e-mail: rungla@kku.ac.th

Received 8 May 2020

Accepted 26 Mar 2021

\begin{abstract}
To get more scientific information to support the medicinal uses of Ipomoea batatas, I. carnea, and I. pescaprae, phytochemical constituent analysis, toxicity and detoxification testing on normal and poisoned human cells, and ion channel inhibition using VGSCs, VGKCs and hERG channel were investigated. GC-MS and HPLC analysis were used for phytochemical screening and measuring the major compounds in $100 \mathrm{~g}$ leaf samples, which were 53.15$1446.93 \mathrm{mg}$ oleamide in I. batatas - I. pes-caprae, $1.51-59.57 \mathrm{mg}$ phytol in I. batatas - I. pes-caprae, and $39.04 \mathrm{mg}$ $\alpha$-amyrin and $8.09 \mathrm{mg} \beta$-amyrin in $I$. pes-caprae. The MTT assay showed no $\mathrm{IC}_{50}$ value, and the comet assay revealed insignificant DNA damages ( $p>0.05$ ) on normal PBMCs. Detoxification efficacy for rice whisky- and herbicide-exposed cells was tested, and higher cell viability percentages were shown when the poisoned cells were treated with $I$. carnea and I. pes-caprae extracts compared with negative control. The hexane and acetonitrile extracts of I. batatas, I. carnea, and I. pes-caprae inhibited the VGSCs $\left(\mathrm{Na}_{\mathrm{v}} 1.6\right.$ and 1.8) and VGKCs $\left(\mathrm{K}_{\mathrm{v}} 1.1\right.$ and $\left.\mathrm{K}_{\mathrm{v}} 10.1\right)$ channels, but not the hERG channel. The overall results indicated that the pharmacological activities of the studied plant extracts allowed them to be used as an excellent analgesic, an early marker in tumor formation useful for diagnosis and therapy of tumors, and treatments of poison and drug addiction, in addition to their antimicrobial, anti-inflammatory, and antipyretic activities. The plants can be used in daily human life with good cardiac safety and low risk for hERG inhibition.
\end{abstract}

KEYWORDS: Ipomoea species, toxicity testing, detoxification activity, ion channel inhibition

\section{INTRODUCTION}

Vegetables are important sources of essential phytochemicals for humans and their health and function as foods or nutraceuticals. Edible phytochemicals can be consumed in many forms: fresh, cooked, traditional medicine preparations, purified, etc. Many plant species have long been used in medicines and cosmetics in several forms. They have been revealed to contain essential substances, such as oleamide, $\gamma$-sitosterol, phytol, $\beta$-sitosterol, squalene $\alpha$-, $\beta$-amyrin, arctigenin, and arbutin. In our previous work on phytochemical profiles of Artocarpus leaves, in addition to quinic acid and sitosterol, high amount of arbutin and phytol were found [1]. For Ipomoea plants, they have been highly recognized as ornamentals, foods, vegetables, and medicines for a long time.

Many studies have revealed the bioactivities of Ipomoea. For example, hydro ethanol extracts of I. turpethum and I. batatas at $500 \mathrm{mg} / \mathrm{kg}$ administered orally for seven days significantly lowered blood glucose levels in diabetic rats (using alloxaninduced diabetes in the rats) [2]. The antidiabetic activity of these plants was not significantly different from each other. This suggests that different species from the same genera may have similar chemical constituents and pharmacological activities [2]. Accordingly, these Ipomoea species have been used in different parts of the world, illustrating their potential as a source of therapeutic agents against several diseases, such as diabetes, hypertension, dysentery, constipation, fatigue, arthritis, rheumatism, hydrocephaly, meningitis, kidney ailments, and in- 
flammation via their antimicrobial, analgesic, plasmolytic, spasmogenic, hypoglycemic, hypotensive, anticoagulant, anti-inflammatory, psychotomimetic, and anticancer activities [3]. Alkaloids, phenolic compounds and glycolipids are the most common biologically active constituents found in Ipomoea extracts [3]. Ipomoea cairica was phytochemically studied by Ralte et al [4] and they found bioactive compounds in its leaves and flowers, which included alkaloids, sterols, flavonoids, reducing sugars, tannins, saponins, terpenoids, anthraquinones, and glycosides. Plants containing pharmacological substances in high quantity and expected to express a single activity should be further examined via preclinical testing. Cytotoxicity and genotoxicity testing in human peripheral blood mononuclear cells (PBMCs) indicating both chronic and acute toxicities can be preclinical test for safe human consumption [5].

Ion channel assay by two-electrode voltageclamp technique is an alternative method for bioactivity testing ex vivo on a panel of molecular targets, rather than on animals. There are several channel inhibitions, such as voltage-gated sodium channels (VGSCs), voltage-gated potassium channels (VGKCs), and human ether-a-go-go related gene (hERG channel), that vary in their functions and responsibilities within the cells. For a functional example, VGSCs $\left(\mathrm{Na}_{\mathrm{v}} 1.1,1.4,1.5,1.6\right.$, and 1.8) are anesthetics due to their sodium channel blocker activity as revealed by Cummins et al [6]. The reliable ion channel protocol showed a minimum of $15 \%$ of currently used drugs target ion channels [7].

Thus, various uses of the Ipomoea species; I. batatas, I. carnea, and I. pes-caprae; were investigated for their phytochemicals, toxicity, and biological activities in this study.

\section{MATERIALS AND METHODS}

\section{Plant materials}

Leaves of Ipomoea species; including I. batatas, I. carnea, and I. pes-caprae; were collected from a farm in Maha Sarakham Province, Khon Kaen University Campus, and a sea shore of Trat Province, respectively.

\section{Phytochemical extraction, GC-MS analysis and toxicity assessment}

The protocols following the methods of Sirikhansang et al [5] were used for phytochemical extraction, plant extract component analysis via gas chromatography-mass spectrometry (GC-MS),
MTT (3-(4,5-dimethylthiazol-2-yl)-2,5-diphenyltetrazolium bromide) assay for assessing cytotoxicity, and comet assay for assessing genotoxicity performing on human peripheral blood mononuclear cells (PBMCs). The MTT results were revealed by percentage of cell viability, whereas the comet assay results were shown by olive tail moment (OTM) which was the measurement of fragmented DNA amount.

\section{HPLC analysis}

Quantitative analysis of oleamide and phytol in plant extracts was done by high performance liquid chromatography (HPLC).

The leaves were washed and separated into fresh and dried samples. A $2 \mathrm{~g}$ sample was ground into powder, mixed with $10 \mathrm{ml}$ of methanol (HPLC grade), and then filtered through filter paper. The filtrate was used for the HPLC analysis.

The standards (oleamide: Sigma-Aldrich, USA; phytol: Sigma-Aldrich, Germany; $\alpha$-amyrin and $\beta$ amyrin: Sigma-Aldrich, France) were dissolved in methanol at concentrations of $1 \mathrm{mg} / \mathrm{ml}$, except for phytol at $0.91 \mathrm{mg} / \mathrm{ml}$. These solutions were 2 -fold diluted for five levels.

The samples and standards were analyzed by HPLC using a Shimadzu LC-20AD (Japan) model with a quaternary pump, a PAD (SPD-M20A) detector, and a column Inertsil ODS-3 C18, $4.6 \times 250 \mathrm{~mm}$, 5 microns (GLSciences Inc.). A $20-\mu 1$ sample was injected. The mobile phase consisted of methanol and acetonitrile, $30: 70 \mathrm{v} / \mathrm{v}$ for oleamide, $\alpha$-amyrin and $\beta$-amyrin, and 40:60 v/v for phytol. The elutions of oleamide and phytol were carried out at flow rates of 1 and $0.7 \mathrm{ml} / \mathrm{min}$; and detection UV wavelengths were $202 \mathrm{~nm}$ and $210 \mathrm{~nm}$, respectively.

\section{Biological activity testing of plant extracts with MTT and comet assays}

PBMC resistance selection

Toxic substances, including rice whisky (containing 40\% alcohol) and herbicide (containing 10\% bipyridylium), were prepared in serial 10 -fold dilutions for 10 concentrations. Then, the viable PBMCs treated with 5 concentrations of toxin were selected as controls for further experiments on detection of detoxification activity by using MTT and comet assays.

\section{Detoxification activity detection}

The three plant extracts of I. batatas, I. carnea, and I. pes-caprae were tested on PBMCs treated with rice 
whisky and herbicide (poisoned cells) alongside the controls (normal cells). After the MTT and comet protocols, damages to the cells and DNA levels were evaluated as described by Sirikhansaeng et al [5].

\section{Testing of plant extracts with ion channels}

The extracts were tested for their anti-inflammatory activities by two-electrode voltage-clamp technique (TEVC) in the whole cell of Xenopus laevis oocytes with VGSCs $\left(\mathrm{Na}_{\mathrm{v}} 1.1,1.4,1.5,1.6,1.8\right)$, VGKCs $\left(\mathrm{K}_{\mathrm{v}} 1.1,10.1\right)$ and cardiac ion channel (hERG channel).

\section{Preparation of plant extracts and standards}

Hexane and acetonitrile (analytical grade, SigmaAldrich, USA) were used separately for plant extraction. The leaf samples of I. batatas, I. carnea, and I. pes-caprae were rinsed with water and air-dried, then ground into a powder. Powder of each sample was mixed with the solvent at a ratio of $1: 6 \mathrm{w} / \mathrm{v}$ and soaked for $72 \mathrm{~h}$. The mixtures were filtered through filter paper (Whatman No. 1), and solvent in the filtrates was evaporated in a rotary evaporator (Rotavapor R-210, Buchi, Switzerland) at $40^{\circ} \mathrm{C}, 600$ rpm for 1-2 h. Yellow and dark green, viscous crude extracts were obtained. $100 \%$ dimethyl sulfoxide (DMSO) was added until the extracts completely dissolved. The sample solutions were, then, diluted to $0.5 \%$ DMSOs with ND-96 solution $(96 \mathrm{mM} \mathrm{NaCl}$, $1.8 \mathrm{mM} \mathrm{CaCl}_{2}, 1 \mathrm{mM} \mathrm{MgCl}_{2}, 5 \mathrm{mM}$ HEPES, adjusted $\mathrm{pH}$ to 7.5 with $\mathrm{NaOH}$ ) for further ion channels experiments.

Standards, which include arctigenin, cisoleamide, and friedelin (Sigma-Aldrich, Belgium), were dissolved in $0.5 \%$ DMSO (in ND-96 solution) to prepare a $20 \mathrm{mM}$ stock solution and stored at $-20^{\circ} \mathrm{C}$ until needed.

\section{Insertion of recombinant receptors (ion channels) into oocytes}

Stage V-V1 oocytes from female $X$. laevis, received from Laboratory of Toxicology and Pharmacology, University of Leuven, Leuven, Belgium, were stored in ND-96 solution mixed with gentamycin sulphate $(1.25 \mathrm{ml})$ and theophylline $(90 \mathrm{mg})$ at $16^{\circ} \mathrm{C}$ until needed.

The cDNA encoding for channels study was transformed in Escherichia coli. After isolation and linearization of plasmid containing cDNA, the cDNA was transcribed into cRNA by Rneasy MinElute Cleanup (Qiagen 74204) transcription kit and stored at $-80^{\circ} \mathrm{C}$ until needed. The selected oocytes were individually injected with 30-50 ng of corresponding cRNA. The injected oocytes were incubated in ND-96 solution at $16^{\circ} \mathrm{C}$ for $1-4$ days, depending on ion channel sort for adequate cRNA expression. The cells were later used for ion channel inhibition testing by electrophysiological recording.

\section{Heterologous expression of voltage-gated ion channels}

For the expression of the studied ion channels in $X$. laevis oocytes, the linearized plasmids were transcribed using the T7 or SP6 mMESSAGEmMACHINE transcription kit (Ambion, Life Technologies ${ }^{\mathrm{TM}}-$ Carlsbad, USA). The harvesting of stage V-VI oocytes was performed as previously described [8]. The oocytes were injected with $50 \mathrm{nl}$ of $1 \mathrm{ng} / \mathrm{nl}$ cRNA using a micro-injector (Drummond Scientific, USA), then incubated in ND-96 solution supplemented with $50 \mathrm{mg} / 1$ gentamycin sulfate. Wholecell currents from oocytes were recorded $2-5$ days after the injection.

For electrophysiological measurements in oocytes, two-electrode voltage clamp recordings were performed at room temperature $\left(18-22^{\circ} \mathrm{C}\right)$ using a Geneclamp 500 amplifier (Axon Instruments -Sunnyvale, California, USA) controlled by a pClamp data acquisition system (Axon Instruments -Sunnyvale, California, USA) with ND-96 solution as a bath solution. Voltage and current electrodes were filled with $3 \mathrm{M} \mathrm{KCl}$. Resistances of both electrodes were kept between 0.7 and $1.5 \mathrm{M} \Omega$. Elicited currents were sampled at $1 \mathrm{kHz}$ and filtered at $0.5 \mathrm{kHz}$ (for potassium currents) or at $20 \mathrm{kHz}$ and filtered at $2 \mathrm{kHz}$ (for sodium currents) using a four-pole low-pass Bessel filter. Leak subtraction was performed using a $\mathrm{P} / 4$ protocol. $\mathrm{K}_{\mathrm{v}} 10.1$ currents were evoked by $1 \mathrm{~s}$ depolarizations to 0 $\mathrm{mV}$, from a holding potential of $-90 \mathrm{mV}$. Current traces of hERG channels were elicited by applying a $+40 \mathrm{mV}$ pre-pulse for $2 \mathrm{~s}$ followed by a $-120 \mathrm{mV}$ for $2 \mathrm{~s}$. Sodium current traces were evoked by 100 $\mathrm{ms}$ depolarization to $0 \mathrm{mV}$ from a holding potential of $-90 \mathrm{mV}$.

The percent inhibition was calculated by dividing the peak current amplitude (I) of the steadystate extract situation $\left(I_{\text {extract }}\right)$ by the peak current amplitude of the control situation $\left(I_{\text {control }}\right)$. The equation is $\%$ inhibition $=\left(I_{\text {extract }} / I_{\text {control }}\right) \times 100$. All data were analyzed by Clampfit 10.7 (Molecular devices, USA) and Origin 9.0 software (Originlab, USA). Percentage inhibition values are as followed: $0 \%$ inhibition is equal to no inhibitory activity and, thus, $100 \%$ of the current remains; whereas $100 \%$ 


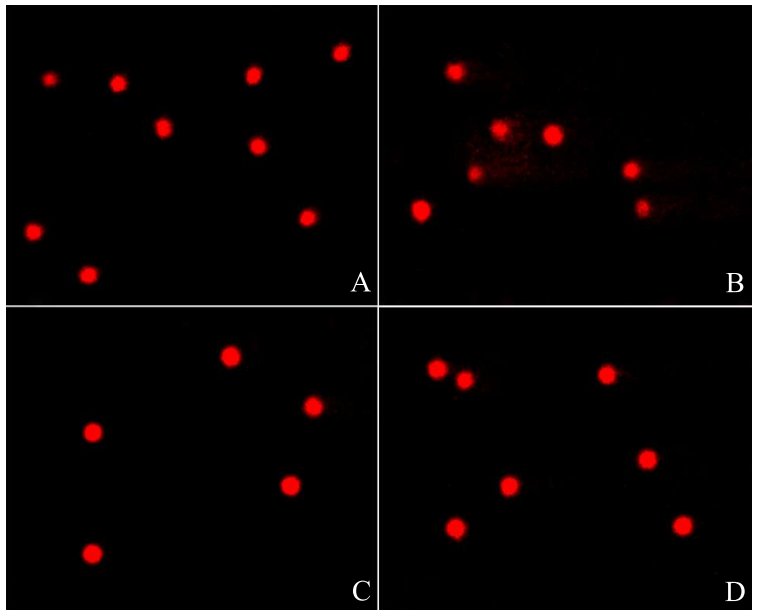

Fig. 1 The comet images $(200 \times)$ of PBMCs treated with herbicide and the treatments; negative control (A); the control for herbicide (B); the treatments in poisoned cells by Ipomoea carnea (C) and I. pes-caprae (D); similar images were not shown.

inhibition is equal to full inhibition of the channels and, thus, $0 \%$ of the current remains.

\section{RESULTS}

As shown in Table 1, the amount of major phytochemicals of interest; i.e. oleamide, $\alpha$ - and $\beta$ amyrin, phytol, and friedelin; derived from GC-MS analysis of leaf ethanol and hexane crude extracts, were more than $10 \%$. The oleamides in I. pescaprae, I. carnea, and I. batatas were at $40.97 \%$, $36.17 \%$, and $26.36 \%$, respectively; whereas $\alpha$ amyrin was at $28.50 \%$ in I. pes-caprae. Phytols were found at $21.58 \%, 13.35 \%$, and $11.76 \%$ in I. batatas, I. carnea, and I. pes-caprae, respectively; while $\beta$ amyrin was at $12.35 \%$ in I. pes-caprae; and friedelin at $10.16 \%$ in I. carnea.

The individual phytochemicals, in $100 \mathrm{~g}$ of dried leaves, were quantified by HPLC. The amount of oleamide and phytol in I. batatas, I. carnea, and I. pes-caprae were $53.15 \mathrm{mg}, 167.22 \mathrm{mg}$, and $1446.93 \mathrm{mg}$ (oleamide); and $1.51 \mathrm{mg}, 3.55 \mathrm{mg}$, and $59.57 \mathrm{mg}$ (phytol); respectively. $39.04 \mathrm{mg}$ of $\alpha$ amyrin was found in I. pes-caprae; while $8.09 \mathrm{mg}$ of $\beta$-amyrin was obtained from I. pes-caprae, (Table 2).

Mass concentrations extracted by ethanol and hexane solvents, which were subjected to serial 10 -fold dilution for five levels, were employed for the MTT assay. The results indicated that there were no $\mathrm{IC}_{50}$ values, meaning no toxicity at the cell level, based on the high percentages of cell viability of $59.67 \pm 0.83-63.34 \pm 0.85$ with $I$. batatas and
$85.41 \pm 0.17-97.13 \pm 0.16$ with $I$. carnea, as shown in Table 3. When evaluating in-depth toxicity by the comet assay, the results showed that the four tested species displayed insignificant DNA damages ( $p>0.05)$, expressed as Olive Tail Moment (OTM) in PBMCs, in comparison to the negative control (Table 3).

PBMCs treated with the two poisons, rice whisky and herbicide, at 10 dilution levels showed resistance via cell viability percentage at $62.54 \pm 0.10-78.45 \pm 0.12 \%$ and $5.92 \pm 0.03-$ $76.27 \pm 0.11 \%$, respectively (Table 4). Therefore, the levels $1-5$ of poison concentrations and PBMC viability percentages, such as $40-0.0004 \%$ and $62.54 \pm 0.10-70.07 \pm 0.10$ for rice whisky and $10-0.0001 \%$ and $5.92 \pm 0.03-67.87 \pm 0.14$ for the herbicide, were selected as controls for further detection of detoxification activity using MTT and comet assays. Detoxification was tested on two species, I. carnea and I. pes-caprae, and not on I. batatas due to its long and widespread history of being an edible plant. The results, demonstrated in the plots of cell viability percentages and extract concentrations, indicated that the extracts increased cell viability percentages, compared with the controls, at the lower dilution levels with 14.62$19.86 \%$ and $20.80-16.27 \%$ when treated with rice whisky; and $13.23-23.69 \%$ and $15.36-13.23 \%$ when treated with herbicide in I. pes-caprae and I. carnea, respectively (Table 4). Accordingly, the OTMs of the poisoned PBMCs after being treated with the two Ipomoea extracts were smaller with a shorter tail than the controls: $0.1717-0.1867$ when treated with rice whisky and 0.1993-0.2005 when treated with herbicide, indicating a decrease in toxicity on the poisoned PBMCs (Table 5 and Fig. 1).

By the TEVC technique, the standards, $100 \mu \mathrm{M}$ arctigenin, and friedelin inhibited two VGSCs $\left(\mathrm{Na}_{\mathrm{v}}\right.$ 1.6 and 1.8) and two VGKCs ( $\mathrm{K}_{\mathrm{v}} 1.1$ and 10.1) channels and slightly inhibited hERG channel at low percentages of $1.9 \%$ and $1.3 \%$, whereas the same concentration of cis-oleamide had no inhibitory effect on the hERG channel (as shown in Fig. 2). The hexane and acetonitrile extracts of I. batatas, I. carnea, and I. pes-caprae resulted in different percentages of inhibition on VGSCs and VGKCs channels. The extracts showed no inhibition on hERG channel, except that the hexane I. carnea extract showed low inhibition percentage at $0.6 \%$. All the inhibition data are shown in Table 6. 
Table 1 Major phytochemical constituents of ethanol (Et) and hexane (He) extracts from the leaves of $I$. batatas, I. carnea, and I. pes-caprae.

\begin{tabular}{|c|c|c|c|c|c|c|c|}
\hline \multirow{3}{*}{ Compound } & \multirow{3}{*}{ Formula } & \multicolumn{6}{|c|}{ Relative content (\%) } \\
\hline & & \multicolumn{2}{|c|}{ I. batatas } & \multicolumn{2}{|c|}{ I. carnea } & \multicolumn{2}{|c|}{ I. pes-caprae } \\
\hline & & Et & $\mathrm{He}$ & Et & $\mathrm{He}$ & Et & $\mathrm{He}$ \\
\hline (Z)-9-Octadecenamide (Oleamide) & $\mathrm{C}_{18} \mathrm{H}_{35} \mathrm{NO}$ & 5.54 & 26.36 & 5.62 & 36.17 & 2.89 & 40.97 \\
\hline Phytol & $\mathrm{C}_{20} \mathrm{H}_{40} \mathrm{O}$ & 21.58 & 2.06 & 13.35 & 1.22 & 11.76 & 2.37 \\
\hline$\beta$-Amyrin & $\mathrm{C}_{30} \mathrm{H}_{50} \mathrm{O}$ & - & - & 3.41 & 1.01 & 12.25 & 3.35 \\
\hline$\alpha$-Amyrin & $\mathrm{C}_{30} \mathrm{H}_{50} \mathrm{O}$ & - & - & 5.66 & 1.23 & 28.50 & 7.21 \\
\hline Friedelin & $\mathrm{C}_{30} \mathrm{H}_{50} \mathrm{O}$ & 7.02 & 2.21 & 10.16 & 1.19 & 3.26 & 0.55 \\
\hline
\end{tabular}

Table 2 Amount of the major chemicals in the dried leaf extracts resulted from the HPLC analysis.

\begin{tabular}{lrrcc}
\hline \multirow{2}{*}{ Plant extract } & \multicolumn{5}{c}{ Amount (mg/100 g sample) } \\
\cline { 2 - 5 } & Oleamide & Phytol & $\alpha$-Amyrin & $\beta$-Amyrin \\
\hline I. batatas & 53.15 & 1.51 & - & - \\
I. carnea & 167.22 & 3.55 & - & - \\
I. pes-caprae & 1446.93 & 59.57 & 39.04 & 8.09 \\
\hline
\end{tabular}

\section{DISCUSSION}

The Ipomoea genus is very interesting, as several species of this genus; including the three studied species I. batatas, I. carnea, and I. pes-caprae; can be used as foods, medicines, and ornamental plants. Most of these benefits are only known for, but lack of comprehensive information on their toxicity and bioactivity at preclinical levels, rather than on animals. We strived to overcome this deficit of information with this study.

The phytochemical investigation of these species is the first to reveal levels of the most interesting substance, oleamide, which peaked at $40.97 \%, 36.17 \%$, and $26.36 \%$ in I. pes-caprae, I. carnea, and I. batatas, respectively. These high oleamide quantities are expected to be expressed in a single unit, which is expected to be one of the active phytochemicals [9]. However, the experiment on oleamide activity merits further study given its use for treatments of Alzheimer's disease, stress, deep sleep, and appetite induction [10]. Recently, the anti-inflammatory effect of oleamide has been shown [11-13]. Additionally, phytol was present at $21.58 \%$ in I. batatas, $13.35 \%$ in $I$. carnea, and $11.76 \%$ in I. pes-caprae; but the amount was not high enough to functionally support the bioactivities of the plants. However, phytol could be easily produced from the degradation of chlorophyll, giving it an important function as a precursor for the biosynthesis of tocopherols, a kind of vitamin $\mathrm{E}$ [14]. Accordingly, vitamin $\mathrm{E}$ is useful for cell health and can help decrease cell aging [15]. As a result, consumers have a good source of high level phytol and tocopherol, which leads to the aforementioned treatments, especially for poisonings and drug addiction. Two other substances, $\alpha$-amyrin and $\beta$-amyrin, in I. pes-caprae were also present in moderate amounts, $28.50 \%$ and $12.25 \%$, respectively. They are bioactive compounds commonly found in several plants. The compounds have shown antimicrobial and antiinflammatory activities [16], which are consistent with the use of the plant in Thailand. I. pes-caprae grows along the beach and is commonly used to relieve pain from the jellyfish toxin at sea. It also displayed antihistamine activity [17].

For each compound and plant, the specific amount (mg) of oleamide, phytol, $\alpha$-amyrin, and $\beta$ amyrin were measured by HPLC. The results showed low to high amounts of oleamide and phytol in I. batatas, I. carnea, and I. pes-caprae. Both $\alpha$ - and $\beta$-amyrins were shown only in I. pes-caprae. Here, I. pes-caprae species is the most interesting for human consumption and its high amount of oleamide, phytol, $\alpha$-amyrin, and $\beta$-amyrin. Therefore, if the three studied plants are not toxic to humans, the leaves of the plants containing these compounds should be beneficial for human health. To support the use of these important phytochemicals, preclinical testing at the cell level was further performed with the MTT assay. The results strongly suggested their safety by presenting no $\mathrm{IC}_{50}$ values, indicating high cell viability of $59.67 \pm 0.83-63.34 \pm 0.85$ in I. batatas to $85.41 \pm 0.17-97.13 \pm 0.16$ in I. carnea. Further steps for safe human use, such as preclinical testing at the genetic level and a comet assay, strongly suggested that the plants were nontoxic to normal human cells (PBMCs). Thus, they may be safely applied for the treatment of diseases. 
Table 3 Mass concentrations, MTT and level of DNA damage expressed as Olive Tail Moment (OTM) in PBMCs after treatment with Ipomoea leaves extracted by ethanol and hexane solvents.

\begin{tabular}{lcccc}
\hline Sample & $\begin{array}{c}\text { Mass concentration } \\
(\mathrm{mg} / \mathrm{ml})\end{array}$ & \% Cell viability & $\begin{array}{c}\text { Olive tail moment } \\
\text { (Median } \pm \text { SD) }\end{array}$ & $p$-Value \\
\hline Negative control & - & - & $0.0008 \pm 0.0184$ & - \\
Positive control & - & - & $26.6078 \pm 27.4582$ & - \\
I. batatas ethanol extract & 0.63 & $77.17 \pm 0.11-92.56 \pm 0.10$ & $0.0010 \pm 0.0067$ & 0.0726 \\
I. batatas hexane extract & 2.94 & $73.35 \pm 0.16-90.23 \pm 0.36$ & $0.0011 \pm 0.0078$ & 0.3295 \\
I. carnea ethanol extract & 1.25 & $59.67 \pm 0.83-63.34 \pm 0.85$ & $0.0011 \pm 0.0105$ & 0.1036 \\
I. carnea hexane extract & 0.25 & $74.86 \pm 0.13-99.25 \pm 0.18$ & $0.0011 \pm 0.0142$ & 0.0570 \\
I. pes-caprae ethanol extract & 10.00 & $69.42 \pm 0.26-89.03 \pm 0.24$ & $0.0012 \pm 0.0087$ & 0.0528 \\
I. pes-caprae hexane extract & 0.16 & $82.60 \pm 0.10-96.17 \pm 0.13$ & $0.0011 \pm 0.0157$ & 0.1148 \\
\hline
\end{tabular}

Table 4 Viability percentages of PBMCs comparing between the cells exposed to poisons and poisoned cells treated with $I$. carnea and $I$. pes-caprae extracts showing higher viability percentages.

\begin{tabular}{lccrc}
\hline Plant extract & Poison & Concentration (\%) & \% Cell viability \pm SD & \% Cell viability increasing \\
\hline \multirow{2}{*}{ Control } & rice whisky & $40-0.0004$ & $69.13 \pm 0.10-79.76 \pm 0.16$ & - \\
& herbicide & $10-0.0001$ & $5.99 \pm 0.02-76.91 \pm 0.16$ & - \\
\hline \multirow{2}{*}{ I. carnea } & rice whisky & $40-0.0004$ & $83.51 \pm 0.23-92.74 \pm 0.24$ & $20.80-16.27 \%$ \\
& herbicide & $10-0.0001$ & $6.91 \pm 0.03-89.39 \pm 0.23$ & $15.36-13.23 \%$ \\
\hline \multirow{2}{*}{ I. pes-caprae } & rice whisky & $40-0.0004$ & $79.24 \pm 0.20-95.60 \pm 0.13$ & $14.62-19.86 \%$ \\
& herbicide & $10-0.0001$ & $6.80 \pm 0.02-95.13 \pm 0.10$ & $13.52-23.69 \%$ \\
\hline
\end{tabular}

Table 5 The level of DNA damage expressed as Olive Tail Moment (OTM) in comparing between the cells exposed to poisons and poisoned cells treated with I. carnea and I. pes-caprae extracts.

\begin{tabular}{lccc}
\hline Plant extract/control/poison & $\begin{array}{c}\text { OTM } \\
\text { (Median } \pm \text { SD) }\end{array}$ & $\begin{array}{c}\text { The difference } \\
\text { OTM shorter }\end{array}$ \\
\hline \multirow{2}{*}{ Control } & $\begin{array}{c}\text { negative control } \\
\text { rice whisky } \\
\text { herbicide }\end{array}$ & $\begin{array}{c}0.0141 \pm 0.0243 \\
0.2009 \pm 0.1277\end{array}$ & - \\
& $0.2246 \pm 0.1686$ & - \\
\hline \multirow{2}{*}{ c carnea } & rice whisky & $0.0292 \pm 0.0356$ & 0.1717 \\
& herbicide & $0.0253 \pm 0.0314$ & 0.1993 \\
\hline \multirow{2}{*}{ I. pes-caprae } & rice whisky & $0.0142 \pm 0.0225$ & 0.1867 \\
& herbicide & $0.0241 \pm 0.0263$ & 0.2005 \\
\hline
\end{tabular}

For preliminary detoxification activity testing in the preclinical trial, the two widely studied species, I. carnea and I. pes-caprae, were used to treat the rice whisky- and herbicide-poisoned PBMCs. Positively, the results showed an increase in viability percentages of poisoned PBMCs compared with the controls; and the reduced tail length of OTM values indicated reduced DNA toxicity.

In summary, the preclinical level based on toxicity and activity tests indicated that the two studied plants are safe for human consumption and help in detoxifying alcohol- and herbicide-exposed cells. In addition, their safety at the clinical level is known, as they have long been consumed following the us- ages of $I$. pes-caprae leaves mentioned by the Useful Tropical Plants Database and Manigauha et al [18]. I. carnea has been used in humans [19]. Then a toxin was found in the leaves that could cause severe damages to the intestine, liver, and kidney of a freshwater fish, the guppy (Poecilia reticulata), resulting in its mortality [20]. Nonetheless, these toxic properties of $I$. carnea did not match the phytochemicals they contained, the potentially good properties of oleamide, $\alpha$-amyrin, $\beta$-amyrin, and phytol. In addition to its nontoxicity and ability to reduce toxicity in the poisoned PBMCs, I. carnea was considered beneficial to humans when exposed to alcohols or herbicides. Leaves of the most interesting species, I. pes-caprae, have long been used in Thai traditional medicine, and new scientific information on these substances show that they are nontoxic, have detoxification activities and can be used naturally in daily life.

Additionally, the cultivated and economic species, I. batatas, has been used for its roots, and its leaves are consumed as vegetables around the world. Thus, it can be used in an attempt to reduce malnutrition [21].

As the studied Ipomoea species are rich in useful bioactive compounds, they are attractive sources for new leads in drug discovery. The I. batatas, I. carnea, and I. pes-caprae extracts; containing oleamide, $\alpha$ - 

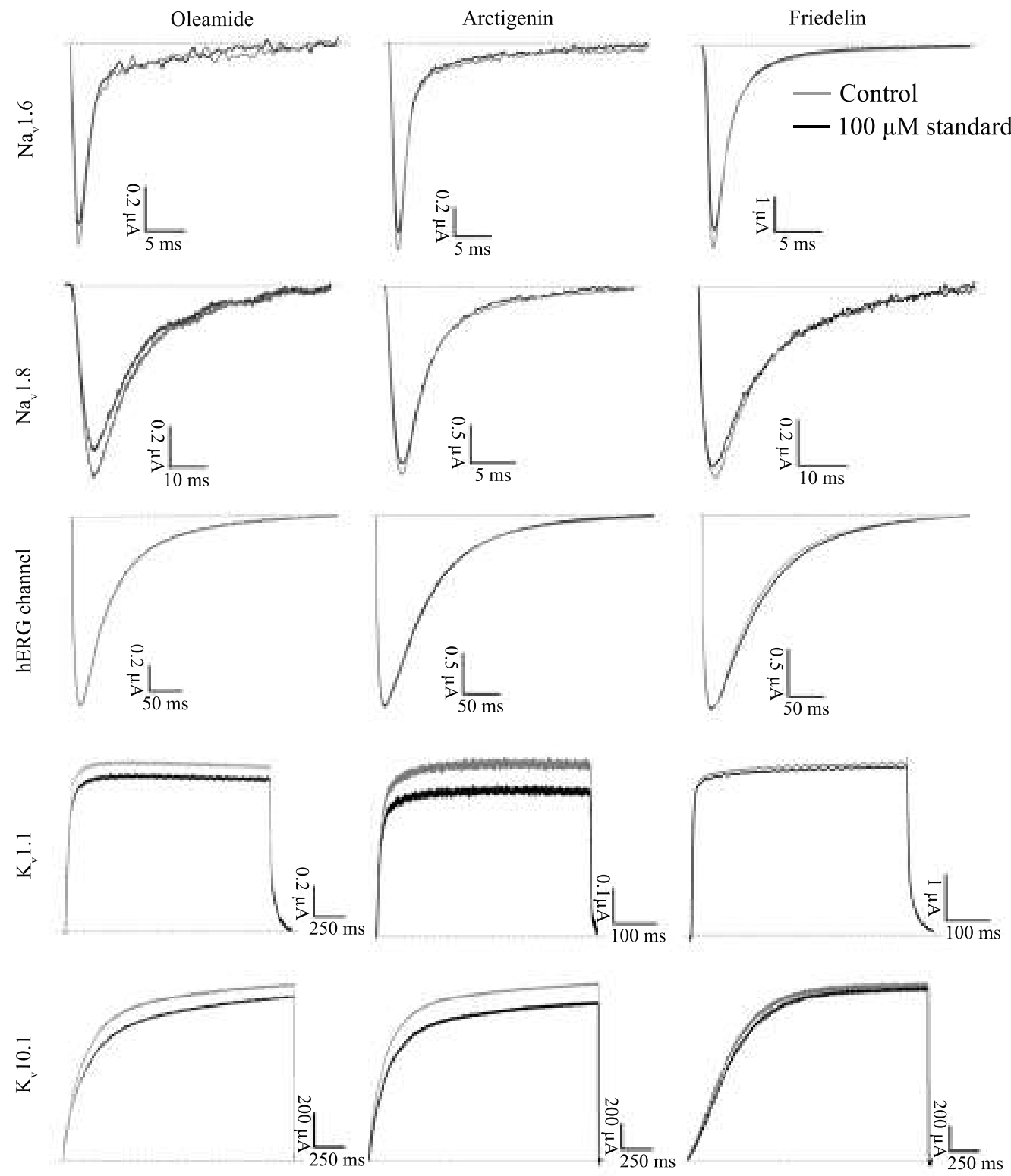

Fig. 2 The effect of cis-oleamide, arctigenin and friedelin standards on voltage-gated sodium $\left(\mathrm{Na}_{\mathrm{v}} 1.6\right.$ and 1.8$)$, voltagegated potassium $\left(\mathrm{K}_{\mathrm{v}} 1.1\right.$ and 10.1) and hERG channels; the effects of I. batatas, I. carnea, and I. pes-caprae extracts were not shown.

and $\beta$-amyrins, phytol, and friedelin; can be standardized, tested for overall pharmacological activity, and clinically tested for treating different clinical conditions through ion pathway. This pathway is a reliable treatment target, with $15 \%$ of currently used drugs targeting ion channels [6]. From our results, the studied plant extracts inhibited VGSCs, $\mathrm{Na}_{\mathrm{v}} 1.6$ and 1.8, as shown by percentage inhibition in Table 6. These appear consistently with the study of Cummins et al [6], revealing their action as anesthetics by being sodium channel blockers. So, these studied plants have been proven to be an excellent analgesic, used for the treatment of epilepsy, central neuropathic pain, atrial fibrillation, ventricular fibrillation, ataxia, and neuropathic pain [22] with good cardiac safety as shown by the inhibition percentage of $0.6 \%$ in hERG channel. Additionally, the three studied plant extracts have 
Table 6 Percentage inhibition on voltage-gated ion channels (VGSCs: $\mathrm{Na}_{\mathrm{v}} 1.6$ and 1.8; VGKCs: $\mathrm{K}_{\mathrm{v}} 1.1$ and 10.1 ; and hERG) of oleamide, arctigenin, friedelin standards, and hexane and acetonitrile leaf extracts of I. batatas, I. carnea, and I. pes-caprae.

\begin{tabular}{|c|c|c|c|c|c|}
\hline \multirow{2}{*}{ Test sample } & \multicolumn{5}{|c|}{$\%$ Inhibition on voltage-gated ion channels } \\
\hline & $\mathrm{Na}_{\mathrm{v}} 1.6$ & $\mathrm{Na}_{\mathrm{v}} 1.8$ & $\mathrm{~K}_{\mathrm{v}} 1.1$ & $\mathrm{~K}_{\mathrm{v}} 10.1$ & hERG \\
\hline Oleamide & 21.9 & 37.2 & 15.8 & 30 & 0 \\
\hline Arctigenin & 27.8 & 11.9 & 18.9 & 17.6 & 1.9 \\
\hline Friedelin & 11.9 & 19.9 & 6.9 & 8.8 & 1.3 \\
\hline I. batatas hexane & 9.6 & 21.6 & 8.1 & 10 & 0 \\
\hline I. batatas acetonitrile & 7.8 & 16 & 13.1 & 12.6 & 0 \\
\hline I. carnea hexane & 13 & 15 & 11.4 & 16.5 & 0.6 \\
\hline I. carnea acetonitrile & 10 & 14.7 & 12.4 & 10.2 & 0 \\
\hline I. pes-caprae hexane & 12.8 & 19.8 & 9.6 & 23.9 & 0 \\
\hline I. pes-caprae acetonitrile & 7.2 & 13.3 & 11.8 & 16.9 & 0 \\
\hline
\end{tabular}

$\mathrm{K}_{\mathrm{v}} 1.1$ activity that may contribute to heart intrinsic function [23]; and $\mathrm{K}_{\mathrm{v}} 10.1$ activity, which has a plethora of research on cancer biology as an early marker in tumor formation, may be useful for tumor diagnosis and therapy [24].

This study on I. batatas, I. carnea, and I. pescaaprae showed the pathway for safe human consumption and health as nutraceuticals and natural medicines. Their bioactive substances will have important impacts, and their pharmacological activity can also be predicted from their effects on the studied ion channels.

Acknowledgements: U.A. and A.C. are funded by the Thailand Research Fund and Khon Kaen University through the Royal Golden Jubilee PhD Program (Grant No. PHD/0182/2557). J.T. was funded by GOC2319N and GOA4919N (F.W.O. Vlaanderen) and CELSA/17/047 (BOF, KU Leuven). S.P. is supported by KU Leuven funding (PDM/19/164). Additionally, the research was partially funded by Research and Academic Services, Khon Kaen University.

\section{REFERENCES}

1. Kaewduangdee S, Chaveerach A, Tanee T, Siripiyasing P, Sudmoon R (2020) Effect of dried ethanol extract of arbutin-containing leaves from Artocarpus on tyrosinase inhibition and postharvest preservation. ScienceAsia 46, 420-428.

2. Raut NA, Kasliwal AR, Gaikwad NJ (2014) Evaluation of antidiabetic potential of Ipomoea turpethum R.Br. and Ipomoea batata L. (Convolvulaceae) in alloxan induced diabetes in rats: a comparative study. Res $J$ of Pharm Biol Chem Sci 5, 137-141.

3. Meira M, da Silva EP, David JM, David JP (2012) Review of the genus Ipomoea: traditional uses, chem- istry and biological activities. Braz J Pharmacogn 22, 682-713.

4. Ralte V (2007) Evaluation of phytochemical contents of Ipomoea cairica (L) Sweet: a qualitative approach. Sci Vis 14, 145-151.

5. Sirikhansaeng P, Tanee T, Sudmoon R, Chaveerach A (2017) Major phytochemical as $\gamma$-sitosterol disclosing and toxicity testing in Lagerstroemia species. Evid Based Complement Alternat Med 2017, ID 7209851.

6. Cummins TR, Waxman SG, Wood JN (2019) Sodium Channels and Pain, The Oxford Handbook of the Neurobiology of Pain, Oxford University Press, Oxford Handbooks Online.

7. Garcia ML, Kaczorowski GJ (2016) Ion channels find a pathway for therapeutic success. Proc Natl Acad Sci USA 113, 5472-5474.

8. Peigneur S, da Costa Oliveira C, de Sousa Fonseca FC, McMahon KL, Mueller A, Cheneval O, Cristina Nogueira Freitas A, Starobova H, et al (2021) Small cyclic sodium channel inhibitors. Biochem Pharmacol 183, ID 114291.

9. Mohamed I, Shuid A, Borhanuddin B, Fozi N (2012) The application of phytomedicine in modern drug development. Int J of Herb Med 2012, ID 250584.

10. Hachisu M, Konishi K, Hosoi M, Tani M, Tomioka H, Inamoto A, Minami S, Izuno T, et al(2015) Beyond the hypothesis of serum anticholinergic activity in Alzheimer's disease: acetylcholine neuronal activity modulates brain-derived neurotrophic factor production and inflammation in the brain. Neurodegenerative Dis 15, 182-187.

11. Moon SM, Lee SA, Hong JH, Kim JS, Kim DK, Kim CS (2018) Oleamide suppresses inflammatory responses in LPS-induced RAW264.7 murine macrophages and alleviates paw edema in a carrageenan-induced inflammatory rat model. Int Immunopharmacol 56, 179-185.

12. Kita M, Ano Y, Inoue A, Aoki J (2019) Identification of P2Y receptors involved in oleamide-suppressing 
inflammatory responses in murine microglia and human dendritic cells. Sci Rep 9, ID 3135.

13. Ameamsri U, Chaveerach A, Sudmoon R, Tanee T, Peigneur S, Tytgat J (2020) Oleamide in Ipomoea and Dillenia species and inflammatory activity investigated through ion channel inhibition. Curr Pharm Biotechno 22, 254-261.

14. Mach J (2015) Phytol from degradation of chlorophyll feeds biosynthesis of tocopherols. Plant Cell 27, ID 2676.

15. Netscher T (2007) Synthesis of vitamin E. Vitam Horm 76, 155-202.

16. Hernández-Vázquez L, Mangas S, Palazón J, NavarroOcaña A (2010) Valuable medicinal plants and resins: commercial phytochemicals with bioactive properties. Ind Crop Prod 31, 476-480.

17. Thanhamol K (1987) Samunprai Center, Step With The Herbs, Faculty of Pharmaceutical Sciences, Mahidol University, Bangkok, Thailand.

18. Manigauha A, Kharya MD, Ganesh N (2015) In vivo antitumor potential of Ipomoea pes-caprae on melanoma cancer. Pharmacogn Mag 11, 426-433.
19. Fatima N, Rahman MM, Khan MA, Fu J (2014) A review on Ipomoea carnea: pharmacology, toxicology and phytochemistry. $J$ Complement Integr Med 11, 55-62.

20. Wanule DD, Balkhande JV (2012) Effect of ethanolic extract of Ipomoea carnea leaves on guppy, Poecilia reticulata (Peters). Bio Disc 3, 240-242.

21. Sun H, Mu T, Xi L, Zhang M, Chen J (2014) Sweet potato (Ipomoea batatas L.) leaves as nutritional and functional foods. Food Chem 156, 380-389.

22. Waszkielewicz AM, Gunia A, Szkaradek N, Sloczynska K, Krupinska S, Marona H (2013) Ion channels as drug targets in central nervous system disorders. Curr Med Chem 20, 1241-1285.

23. Glasscock E, Voigt N, McCauley MD, Sun Q, Li N, Chiang DY, Zhou XB, Molina CE, et al (2015) Expression and function of $\mathrm{K}_{\mathrm{v}} 1.1$ potassium channels in human atria from patients with atrial fibrillation. Basic Res Cardiol 110, ID 505.

24. Cazares-Ordonez V, Pardo LA (2017) $\mathrm{K}_{\mathrm{v}} 10.1$ potassium channel: from the brain to the tumors. Biochem Cell Biol 95, 531-536. 